\title{
Enhancement of Penaeus monodon shrimp postlarvae growth and survival without water exchange using marine Bacillus pumilus and periphytic microalgae.
}

\begin{abstract}
We have investigated the possibility of using a consortium of marine bacterium and periphytic microalgae to improve the water quality and increase the growth and survival of the shrimp Penaeus monodon in a hatchery system. Three treatments were evaluated for their effect on P. monodon postlarvae (PL) when the culture water was not changed: Bacillus pumilus alone (B); periphytic microalgae alone $(\mathrm{M})$; B. pumilus + periphytic microalgae (BM). P. monodon PL raised in a tank of unchanged water without bacterium and periphytic microalgae served as the control. The water in tanks of the $\mathrm{M}$ and BM treatments had significantly low levels of total ammonia-nitrogen (TAN) (0.03 and $0.01 \mathrm{mg} 1-1$, respectively) and nitrite-nitrogen (NO2-N) $(0.03,0.01 \mathrm{mg} \mathrm{1-1}$, respectively) than that in the $\mathrm{B}$ (TAN 0.80, NO2-N $0.68 \mathrm{mg} \mathrm{1-1)}$ and control (TAN 1.11, NO2-N $1.12 \mathrm{mg} \mathrm{1-1)} \mathrm{tanks.}$ Moreover, PL cultured in tanks $\mathrm{M}$ and BM had significantly higher survival and specific growth rates and a significantly higher resistance to the reverse salinity stress test than those in the B and control tanks. Compared to the control PL, the PL cultured in the BM tanks had significantly higher levels of protein, lipid, polyunsaturated fatty acids, ecosapentaenoic acid, and docosahexaenoic acid. The culture water in tanks BM also contained significantly less Vibrio than the control water. Our results illustrate the beneficial effects of a B. pumilus and periphytic microalgae consortium on improving the water quality and the growth and survival of shrimp PL grown in a hatchery system.
\end{abstract}

Keyword: Bacillus pumilus; Consortium; Penaeus monodon; Periphytic microalgae; Postlarvae. 